Social Work/Maatskaplike Werk Vol 57 No 4; Issue 8

http://socialwork.journals.ac.za/pub

doi:http://dx.doi.org/10.15270/52-2-973

928 IS FOSTER CARE THE SAFE PLACE WE BELIEVE IT TO BE? IF NOT, WHY NOT?

Rankwe Reuben Masha, Petro Botha

Mr Rankwe Reuben Masha, Postgraduate Student, University of South Africa, Pretoria, South Africa.

Prof. Petro Botha, Department of Social Work, University of South Africa, Pretoria, South Africa.

Rankwe Reuben Mash: $\quad$ Reuben.Masha@fssocdev.gov.za or ngwato.mashal4@gmail.com

Petro Botha: Bothap@unisa.ac.za

Foster care is an important part of the child protection system; however, it seems that some foster children are not protected - they are abused and neglected. The aims of this article are to confirm on a small scale whether children in foster care are indeed being abused and neglected and to develop an understanding of factors contributing to the abuse and neglect of these foster children. A qualitative research approach was applied. Findings confirmed the occurrence of abuse and/or neglect and provided information on factors relating to foster parents and the foster care system itself contributing to this phenomenon.

Keywords: abuse, foster children, foster care grant, foster parents, neglect, social workers 


\title{
IS FOSTER CARE THE SAFE PLACE WE BELIEVE IT TO BE? IF NOT, WHY NOT?
}

\author{
Rankwe Reuben Masha, Petro Botha
}

Mr Rankwe Reuben Masha, Postgraduate student, University of South Africa, Pretoria, South Africa.

Prof. Petro Botha, Department of Social Work, University of South Africa, Pretoria, South Africa.

\section{INTRODUCTION}

Foster care is an important strategy that forms part of child protection systems around the world. In the United States of America (USA), 423887 children were placed in foster care in 2019 (Adoption and Foster Care Analysis and Reporting System Report, 2020). In the United Kingdom (UK), 65000 children were in foster care placements in 2020 (The Fostering Network, 2020). By the end of December 2020, 216174 children in South Africa had received the foster care grant (FCG) (South African Social Security Agency, 2020).

Concern about the maltreatment of foster children, including abuse and neglect, have been reported in a number of countries from the late 1970s and the 1980s (Biehal \& Parry 2010). In 1976-1978 a study was done in Arizona (USA) on all maltreatment cases reported during this time. From the data it was suggested that 228 of the 3168 foster children in the area were maltreated. This would imply that $7 \%$ of the USA's children in foster care at that time could have been at risk of maltreatment (Bolton, Laner \& Gai, 1981). Cavara and Ogren (1983) reported that from May 1980 to November 1981125 complaints were received of foster children being abused or neglected in Minneapolis, USA. Farmer and Moyers (2008) reported that there were allegations of physical and emotional abuse committed by the foster parents in the study they conducted. Based on a cross-section of children who were living in kinship and unrelated foster care placements, formal allegations of maltreatment were made against 12 kinship and 6 unrelated foster carers. Two of the unrelated foster placements and five of the kinship placements were terminated (Farmer \& Moyers, 2008). Data from various studies on maltreatment of foster care children in the UK, USA and Australia from 1999-2008 indicated that foster children are abused and neglected; however, Biehal and Perry (2010) came to the conclusion that is difficult to compare results as different units of analysis are used and a distinction is not always made between allegations and confirmed cases of maltreatment. They concluded, however, that the prevalence of maltreatment of foster children ranges between $3 \%$ and $19 \%$ of children in foster care in the UK.

No specific statistics on abuse or neglect of foster children in South Africa could be found. However, several authors have voiced their concerns around this matter. The Child Maltreatment Prevention Readiness Assessment: South Africa (HSRC, 2012) indicated a lack of resources to monitor the trajectory of children in statutory care, placing children "at risk, even in their new, supposedly safe environment". In their article Böning and Ferreira (2013) focus on the crisis in the foster care system, mentioning that foster children are often abused for the foster care grant, and the authors express their concern "that at present children end up in the statutory system while professional responsibility cannot be really accepted for them". Mnisi (2015), in a study of factors contributing to the breakdown of foster care of adolescents, reported that in comparison with parents who did not indicate abuse and neglect of foster children as a factor for breakdown, adolescents reported physical and emotional abuse; misuse of the foster care grant; and sexual abuse by someone who was close to the foster family. The South African child protection services are overwhelmed and Schiller and Strydom (2018) warn that investigations are often rushed without attention to detail, overlooking information important to the safety and development of children.

Although there is clear evidence in the literature of abuse and neglect of foster children in other countries, there seems to be not only a lack of statistical evidence that abuse and neglect of foster children is occurring in South Africa, but also of research into factors that may contribute to such abuse and neglect. The purpose of this article is to confirm on a small scale whether children in foster care are indeed being 
abused and neglected, and to examine the factors that may contribute to this. The next sections provide a literature review of the problem, the research methodology utilised, the findings, conclusions of the study and recommendations. The research confirmed that foster children are indeed abused and neglected, and indicated that factors relating to foster parents, the foster child, the foster parent-foster child relationship, the community, social work foster care services and other organisations play a role. It is clear from the findings that the foster care system needs to be reviewed to minimise or stop the abuse and neglect of children in foster care.

\section{LITERATURE REVIEW AND PROBLEM FORMULATION}

\section{Definition of foster care}

According to sections 180 to 182 of the Children's Amendment Act 41 of 2007 (RSA, 2008), foster care is an alternative care placement that occurs when a child is placed, by a children's court order, with a suitable person, who then becomes a foster parent to the child. The foster parent must be able to provide an environment that is conducive to the child's growth and development. As stated in section 181 of the Children's Amendment Act 41 of 2007, the aim of foster care placement is to care for and protect children by providing them with a safe and healthy environment with optimal support (Gil, 2006; Naicker, 2021).

Section 180 of the South African Children's Act 38 of 2005 (RSA, 2005) states that a child may be placed in foster care with:

(a) a person who is not a family member of the child, (b) with a family member who is not the parent or guardian of the child; or (c) in a registered cluster foster care scheme.

A distinction is thus made between non-kinship foster care, kinship foster care and cluster foster care. This article focuses only on the abuse and neglect of foster children placed in non-kinship and kinship foster care.

\section{Definition and types of abuse and neglect in foster care}

Some sources referred to in the introduction use the concept of "maltreatment" of foster care children. Maltreatment is defined as all forms of physical and/or emotional ill-treatment, sexual abuse, neglect, commercial or other forms of exploitation which are harmful to the child (HSRC, 2021). In this article specific reference is made to abuse and neglect. The Children's Amendment Act No. 41 of 2007 (RSA, 2008) states that a child is abused if any form of detriment or maltreatment is intentionally inflicted on a child such as beating a child or deliberately injuring the child; abusing the child sexually; making the child work or employing a child; or subjecting a child to behaviour that may impair the child psychologically or emotionally. The children that are reported in the researchers' study were abused physically, emotionally and sexually by foster parents or person staying in the foster family. According to the Children's Act 38 of 2005 (RSA, 2005), child neglect means a failure in the exercise of parental responsibility to provide for the basic physical, intellectual, emotional or social needs of the child. When comparing the definitions of the concepts, it seems that "maltreatment" includes all forms of abuse and neglect.

The study by Bolton et al. (1981) did not focus on the types of maltreatment but on the characteristics of the foster parents. The study in Minneapolis identified substantiated and unsubstantiated physical (16 substantiated; 26 unsubstantiated) and sexual abuse ( 5 substantiated; 6 unsubstantiated) as well as neglect (16 substantiated; 26 unsubstantiated) (Cavara \& Ogren, 1983). In the study by Farmer and Moyers (2008) reference was made to physical and emotional abuse. Biehal and Perry (2010) indicated that only a few of the studies on maltreatment of foster children specified the nature of maltreatment. Table 1 is a summary of studies in the UK and Australia (Biehal, Ellison, Baker \& Sinclair, 2010, The Fostering Network, 2004; Hunt, Waterhouse \& Lutman 2008, Nixon \& Verity, 1995; Swain 2006; TarrenSweeney, 2006) that refer to types of abuse and neglect of foster children (Biehal \& Perry, 2010: 23-24). 
TABLE 1

PREVALENCE OF ALLEGATIONS AND SUBSTANTIATED MALTREATMENT

\begin{tabular}{|c|c|c|c|}
\hline Study & Sample size and type & Data source & Type of maltreatment \\
\hline $\begin{array}{l}\text { Allegations against } \\
\text { foster carers } \\
\text { NFCA } \\
\text { Nixon \& Verity, } 1995\end{array}$ & 519 foster carers & Foster carers & $\begin{array}{l}\text { Physical abuse: } 49 \% \text { of allegations } \\
\text { Sexual abuse: } 37 \% \text { of allegations } \\
\text { Neglect: } 8 \% \text { of allegations } \\
\text { Emotional abuse: } 10 \% \text { of allegations }\end{array}$ \\
\hline $\begin{array}{l}\text { Fostering can never be } \\
\text { the same for us } \\
\text { The Fostering } \\
\text { Network, } 2004\end{array}$ & 64 foster carers & Foster carers & $\begin{array}{l}\text { Physical abuse: } 48 \% \text { of allegations } \\
\text { Sexual abuse: } 23 \% \text { of allegations } \\
\text { Poor standards of care: } 25 \%\end{array}$ \\
\hline $\begin{array}{l}\text { Allegations in foster } \\
\text { care } \\
\text { Fostering Network/ } \\
\text { Swain, } 2006\end{array}$ & 1002 foster carers & Foster carers & $\begin{array}{l}\text { Physical abuse: } 52 \% \text { of allegations } \\
\text { Sexual abuse: } 16 \% \text { of allegations } \\
\text { Poor standards of care: } 16 \%\end{array}$ \\
\hline $\begin{array}{l}\text { Kinship care }(U K) \\
\text { study } \\
\text { Hunt, Waterhouse \& } \\
\text { Lutman } 2008\end{array}$ & $\begin{array}{l}113 \text { children in kinship } \\
\text { care }\end{array}$ & Foster carers & $\begin{array}{l}\text { Abuse, neglect and exposure to sexual } \\
\text { activity }\end{array}$ \\
\hline $\begin{array}{l}\text { New South Wales } \\
\text { Tarren-Sweeney, } 2006\end{array}$ & 347 children & Agencies & $\begin{array}{l}\text { Mainly inappropriate discipline or } \\
\text { scapegoating; some severe maltreatment }\end{array}$ \\
\hline $\begin{array}{l}\text { Permanent placements } \\
\text { study } \\
\text { Biehal, Ellison, Baker } \\
\text { \& Sinclair, } 2010\end{array}$ & 37 children & $\begin{array}{l}\text { Children and } \\
\text { carers }\end{array}$ & $\begin{array}{l}\text { Mainly inappropriate discipline or } \\
\text { scapegoating; some severe maltreatment }\end{array}$ \\
\hline
\end{tabular}

The only South African study which could be found referring directly to abuse and neglect of foster children is the postgraduate research done by Mnisi (2015). She interviewed 8 adolescents and 10 foster parents who were involved in foster placements which were terminated. None of the foster parents mentioned abuse or neglect of the foster child, while six adolescents alleged that they suffered from physical and emotional abuse. Two adolescents specifically said that the foster mother was the abuser, while one adolescent indicated that she was emotionally and verbally abused by her grandmother. One incident of sexual abuse was reported.

\section{Factors contributing the abuse and neglect of foster children}

Not all the international sources referred to in the introduction throw light on factors contributing to the abuse and neglect of foster children. In their study Bolton et al. (1981) indicated that foster parents maltreating children are more likely to be older, with a higher income and with higher rates of legal marriage. In the Minneapolis study factors in the foster parents which seemed significant were marital status, having children of their own and the length of being licensed as a foster parent. From the single mothers who were part of the study, $46 \%$ were single, $34 \%$ of the families in the study were childless, and $64 \%$ of the foster parents involved had their foster care license for 4 years of longer. Biehal and Perry (2010) refer to general trends uncovered by studies: allegations of maltreatment seem less in kinship foster care than in non-related foster care; more girls seem to be more likely to be sexually abused, while boys are more likely to be physically abused. Children with disability seem to be more likely to be abused and neglected.

Although the South African authors mentioned in the introduction do not refer to incidences of abuse or neglect in foster care, they warn against a child protection system overwhelmed by extended families relying on the foster care grant (FCG) to provide for the material needs of the family, and insufficient resources to monitor children in statutory care and investment in prevention and early intervention (HSRC, 2012; Schiller \& Strydom, 2018). Böning and Ferreira (2013) also warn that the high caseloads of social workers negatively affects the quality of foster care services, tracking of foster children through the system, and long-term planning based on a foster care plan. These authors indicate that the foster care system in South Africa is in a crisis and question whether it is really serving the best interests of the child. 


\section{Problem formulation}

It is clear from the international literature consulted that foster children are often physically, emotionally and sexually abused and neglected, and that this has serious consequences for foster children (Bolton, $e t$ al., 1981; Biehal \& Perry, 2010; $\quad$ Cavara \& Ogren, 1983; Farmer \& Moyers, 2008). Although mention is made of characteristics of foster parents maltreating foster children, not much could be found in the international literature on factors contributing to the abuse and neglect of children in foster placements (Biehal \& Perry, 2010; Böning \& Ferreira, 2013). Only one South African study could be identified that refers directly to the abuse and neglect of children in foster care (Mnisi 2015), although several authors implied a serious concern for the safety of foster care children (Böning \& Ferreira, 2013; HSRC, 2012;; Schiller \& Strydom, 2018). It can thus be concluded that it is not clear whether children in foster care in South Africa are maltreated and, if so, what the factors are which contribute to this abuse and neglect. The aims of the research were to confirm abuse and neglect of foster children on a small scale and to identify possible factors contributing to this.

The next section covers the methodology used in the study.

\section{RESEARCH METHODOLOGY}

To explore and describe the under-researched topic of this study, namely the abuse and neglect of children in foster care, a qualitative research approach with an explorative, descriptive and contextual research design was applied (Babbie, 2007; Silverman, 2010). Ethical clearance for the study was obtained from the Research and Ethics Committee of the Department of Social Work at Unisa, and permission was granted from the relevant organisations. The population targeted for the study was comprised of social workers employed by the Department of Social Development and one NGO, namely Setshabelo Family and Child Services, which render foster care services in the area of Botshabelo in the Free State Province, South Africa. Male and female social workers, who had more than one year's experience in working with foster care, were willing to participate, were fluent in English or Sesotho, and who resided in Botshabelo and Bloemfontein in the Free State Province were included in the study. These social workers work within the context of foster care were rich sources of information, because they had first-hand experience of foster care - each social worker managed a caseload of more than 100 foster care placements. The researcher utilised purposive sampling to select social workers. A pilot test was undertaken with two social workers to ensure that the interview schedule provided sufficient information. A total of 13 interviews were conducted with social workers from the two aforementioned organisations. Semistructured interviews were conducted to gather information and data were analysed using the framework proposed by Tesch (Creswell, 2009). The ecological systems perspective providing a person-inenvironment view that recognises the impact of environmental factors on human functioning was used as the theoretical framework (Hall 2013; Paat, 2013). The researcher used the verification method described by Maree (2007) and abided by the ethical considerations of informed consent, confidentiality, anonymity and the debriefing of participants in this study. Narratives relating to the topic with literature control are discussed next.

\section{FINDINGS}

Participating social workers were asked the following questions:

- How many cases of abuse and neglect of foster care children by their foster parents have you encountered during the last year?

- Discuss the type of abuse and neglect you encountered.

- What in your perspective are the factors contributing to abuse and neglect of foster children?

The participants referred to factors related to the foster parent, the foster child, the foster parent-child relationship, the child's family, the community, foster care services and other organisations. For the purpose of this article, we will refer only to factors related to the foster parents and foster care services. 
TABLE 2

\section{THEMES RELATED TO THE ABUSE AND NEGLECT OF FOSTER CHILDREN}

\begin{tabular}{|c|c|}
\hline Theme & Sub-theme \\
\hline \multirow[t]{4}{*}{ 1. Types of abuse and neglect } & 1.1 Physical neglect \\
\hline & 1.2 Physical abuse \\
\hline & 1.3 Emotional neglect and abuse \\
\hline & 1.4 Sexual abuse and rape \\
\hline \multirow{6}{*}{$\begin{array}{l}\text { 2. Factors related to foster parents that contribute } \\
\text { to neglect and abuse }\end{array}$} & 2.1 Misuse of the FCG \\
\hline & 2.2 Poverty and unemployment of foster parents \\
\hline & 2.3 Inappropriate disciplining of foster children \\
\hline & 2.4 Foster parents' own experience of abuse \\
\hline & 2.5 Foster parents' lack of understanding of foster care \\
\hline & 2.6 Foster parents' lack of understanding of foster child's needs \\
\hline \multirow{6}{*}{$\begin{array}{l}\text { 3. Factors in social work foster care services that } \\
\text { contribute to neglect and abuse }\end{array}$} & 3.1 High foster care caseloads per social worker \\
\hline & $\begin{array}{l}\text { 3.2 Shortage of manpower and too few resources to do social work } \\
\text { effectively }\end{array}$ \\
\hline & 3.3 Forced foster care placements \\
\hline & 3.4 Inadequate assessment and training of foster parents \\
\hline & $\begin{array}{l}3.5 \text { Inadequate monitoring, supervision and support of foster care } \\
\text { placements }\end{array}$ \\
\hline & $\begin{array}{l}\text { 3.7 Inadequate provision for differences between foster child and foster } \\
\text { family during placement }\end{array}$ \\
\hline
\end{tabular}

The social workers who participated in the study did not keep a statistical record or register of the neglect and abuse of foster children served by their offices. The table below provides a summary of the number of cases of abuse and neglect of foster care children identified by the participants during the year 20162017 in the Botshabelo Township. It was not clear why social worker 1 reported such high numbers.

\section{TABLE 3}

\section{ESTIMATED NUMBER OF CASES OF ABUSE AND/OR NEGLECT IDENTIFIED BY PARTICIPANTS}

\begin{tabular}{|l|l|}
\hline Social worker participants & Number of cases reported of neglect and abuse \\
\hline Social worker 1 & Two hundred and five (205) cases were reported as neglect and abuse. \\
\hline Social worker 2 & $\begin{array}{l}\text { One (1) case was physical abuse, one (1) case was sexual abuse, and six } \\
\text { (6) cases were neglect. }\end{array}$ \\
\hline Social worker 3 & Six (6) cases including physical abuse, emotional abuse and neglect \\
\hline Social worker 4 & Six (6) cases were reported as neglect and one (1) case were sexual abuse \\
\hline Social worker 5 & Six (6) cases of neglect and abuse \\
\hline Social worker 6 & Three (3) cases of neglect \\
\hline Social worker 7 & Two (2) cases of physical and emotional abuse and neglect \\
\hline Social worker 8 & One (1) case of neglect \\
\hline Social worker 9 & One (1) case of physical abuse \\
\hline Social worker 10 & Two (2) cases of neglect \\
\hline Social worker 11 & One (1) case of neglect \\
\hline Social worker 12 & One (1) case of emotional abuse \\
\hline Social worker 13 & Two (1) cases of neglect and physical abuse \\
\hline
\end{tabular}

To compare the reported incidences with international research, detailed statistics need to be available, with incidences being compared to the foster care caseloads of the social workers. The absence of an official record or register is a serious gap in foster care services and indicates a lack of awareness of the extent and implication of the alleged abuse and neglect of foster care children. If there is no awareness and account of a problem, no steps can be taken to prevent and address the problem. 


\section{Theme 1: Types of neglect and abuse encountered}

The participants referred to physical neglect, physical abuse, emotional neglect and abuse as well as sexual abuse and rape.

\section{Sub-theme 1.1 Physical neglect}

From comments by the participants, it was apparent that foster parents neglect foster children as they do not provide for the basic needs of foster children. It was the opinion of social workers that foster parents exploit the FCG.

Even if when the child has no proper clothes is a form of neglect. When it is winter the child wore $t$-shirt that are not warm. (EPT)

The child was not clean, the child did not have food, and was just left the child alone, and it is neglect. (MPT)

Yes, like that one I mentioned uncle as a foster parent, he was receiving the grant, but the foster children were not having clothes, food and toiletry. (KPT)

The study by Dhludhlu and Lombard (2017) confirmed that the foster care grant is not always utilised in the interest of the child and that families often depend on the grant as a form of poverty alleviation. As the FCG is seen as a short-term solution for poverty eradication, social workers should actively empower people in their own development. The HSRC (2012) stresses the importance of child maltreatment prevention programmes, but indicates that while appropriate South African policies are in place, implementation is still inadequate.

\section{Sub-theme 1.2 Physical abuse}

Physical abuse of foster care children was confirmed by participants in this study. Foster parents were reported to have beaten the children to a point where there are visible marks or scratches:

The child was physically abused with some marks. (JPT)

He [foster parent] was beating him [the foster child] with his hands, like when he speaks to him, he was beating him with fists and slapping him, he was not using the belt, that is the case of physical abuse I have encountered. (LPT)

Another case of physical abuse, the foster child was brutally beaten. The child ended up in hospital. (IPT)

There is consistency between what the participants mentioned and the definition of physical abuse in the literature. Physical abuse is described as non-accidental physical injury, which includes severe beating, biting, broken bones, strangulation, welts and/ or body injuries (Pretorius \& Pistorius 2012). In addition, physical abuse is described "as the act of causing physical injury, ranging from excessive discipline to beatings and scalding" (McGuinness \& Schneider 2007: 298). In these story lines participants referred to visible signs of abuse. In contrast Biehal and Perry (2010) distinguish between allegations of abuse and confirmed abuse. This will always be an important consideration.

\section{Sub-theme 1.3 Emotional neglect and abuse}

These story lines showed that foster children were being burdened by emotional abuse. Foster parents verbally abused the children and did not show caring by providing for their physical needs. The foster family thus did not serve its purpose for some of the foster children.

No, it was emotional [abuse] because the child was not getting love from the foster parent and when the child was from school, the foster child would find no one in the house with no food. The uncle was out looking for a job so they can have food. (CPT)

Some [foster parents] abuse foster children emotionally by saying, 'I'm not your mother, I'm not the one who caused your mother's death', those painful words are uttered by foster parents. (FPT) 
Foster parents have bad words they utter to foster children like 'your mother is dead, you see, you are irritating'; these are said to foster children. For example, girl foster children are told that they are going in the same path as that one of their mothers, 'you will die like her because she was doing exactly what you are doing'. (DPT)

The view of Pretorius and Pistorius (2012) correlates with that of the participants by indicating that emotional abuse entails acts omission as well as commission. The authors explain that acts of omission (what is not done, or may be a lack of interest or support for the child, lack of physical contact) and commission (what is done, or may be making the child a scapegoat; criticising and constantly belittling the child; name calling; making negative comparisons to others; shaming a child, telling a child he/she is not good, worthless, bad) are in the end damaging. According to the Scottish Government (2010:14), foster parents emotionally neglect and abuse their children by not being supportive and setting up unrealistically high or inappropriate expectations for the developmental level of foster children. Furthermore, emotional abuse is the failure of the parent or caregiver to provide a developmentally and supportive environment for the child, which may have a detrimental effect on the child's physical, mental, social and spiritual health (World Health Organisation and International Society for Prevention of Child Abuse and Neglect 2006).

\section{Sub-theme 1.4 Sexual abuse and rape}

This study revealed a shocking incident of sexual abuse of a foster child where the child was raped 52 times by one perpetrator, and without any recourse help to such an extent that the child was hospitalised. The perpetrators referred to by participants were family members or partners of the foster parent.

It happened that I was not involved as the area social worker, the police came to report to me by requesting a report from me. The perpetrators raped the foster child 52 times. The child is still hospitalised. (GPT)

Because I remember in 2014, I dealt with a sexual abuse case whereby the foster child was sexually abused by partner of a foster parent. (IPT)

Foster parents should stand up for the foster child, they [foster parents] normally leave many abuses happening to the foster child because perpetrators are their children, even the rapes are there, the uncles rape foster children and tell them to be silent about the issue. (DPT)

Pretorius and Pistorius (2012:11) describe sexual abuse as occurring:

when a developmentally immature child or adolescent is sexually exploited or allowed to be directly or indirectly involve in unwanted sexual activities they do not fully comprehend by force, intimidation or deception.

The finding that the perpetrator is not always the foster parents, but often somebody from the foster home, is confirmed by Biehal and Parry (2010).

\section{Theme 2: Factors related to foster parents that contribute to abuse and neglect}

Six sub-themes that relate to foster parents emerged.

\section{Sub-theme 2.1 Misuse of the FCG}

Participants indicated that some foster parents misuse the FCG.

The fact that foster children bring income in the family, parents force that the children be placed under their care for the reason of getting the income (grant). As a result of that, foster children had no support and no love from foster parents. (CPT)

Foster parents use the foster care grant as an income generator; hence the abuse enters because the parent has no time for the child. (PT)

You know, our society appreciate foster children because of money, they don't care for the children, especially when the children start to be vocal, by reporting that I'm not taken care of. 
That is when they start to abuse and neglect them, saying to the foster child you told the social worker that I don't provide for you, see for yourself what you can eat... (JPT)

There are allegations that some foster parents only take care of orphaned children because they receive the FCG (Böning \& Ferreira 2013; Naicker, 2021). According to the Guidelines for Effective Management of Foster Care in South Africa (Department of Social Development, 2009), the purpose of the FCG is to help the foster parent to meet the needs of the foster child. The guidelines further highlight that foster parents should take into consideration that the FCG might not fulfil all the foster child's needs; it should be seen as supplementing the income of the foster family. The Department of Social Development (2012a) indicates that it becomes a critical challenge when foster parents lack financial means and rely on the FCG, as the grant is not adequate to provide for the whole family. This study found that the FCG is not seen as a supplement to support the placement, but as a source of income or money to boost the foster parent.

\section{Sub-theme 2.2 Poverty and unemployment of foster parents}

This sub-theme closely relates to the previous sub-theme. The findings revealed that the unemployment of foster parents affects foster children negatively. The needs of the foster children are not catered for as the foster parents are unemployed and depend on the FCG. The following comments confirm this subtheme:

The second one [case] was not intentional neglect because the foster parent is unemployed with three children of her own. The family depends on the child support grant and foster care grant and on top of that she was owing loan sharks money... The needs of the child and family depend on the grant so some foster parents don't neglect deliberately it's because of other circumstances. (CPT)

One that I know is the issue of unemployment, most foster parents are unemployed and this limits them in terms of understanding the purpose of the grant, which is for the needs of the child not those of the family; it is not enough for the family, that causes the money to be diverted... (EPT)

Unemployment contributes to neglect, it is because when she comes to foster a child or those who are already fostering children and those cases that we inherited from Department of Social Development as Setshabelo, they came with the intention that the money they are going to get will assist them to live, to support and sustain their families. (LPT)

FCG is supposed to be part of the child protection system and not a poverty alleviation grant (Kanyane, 2015). It is reported that the FCG is used as a poverty alleviation grant for orphans in kinship care (Jamieson, Berry \& Lake, 2017). On 23 December 2020 the Social Assistance Amendment Act was passed by Parliament, empowering the Minister, with the concurrence of the Minister of Finance, to prescribe an additional payment linked to a social grant. The Department intends to use this to provide an additional amount for the Child Support Grant (CSG) recipients who are orphaned and live with family in anticipation of diverting them from the foster care system (Naicker, 2021).

\section{Sub-theme 2.3 Inappropriate disciplining of foster children}

Feedback from participants revealed that foster parents appear to be poorly equipped or unable to parent foster children. Foster parents seem to be confused about how to handle or discipline foster children.

They don't know the meaning of abuse and discipline, they mix them, and it resulted in using fists on the child saying 'I'm disciplining the child'. (LPT)

According to the cases I explained to you, you may find that foster parents are feeling that it is not their biological children, they don't discipline them. I will say foster parents don't know how to handle foster care children because they have already classified the children, they put them in a box, which is the thing that is angering the foster parents. (BPT) 
The child should not make any mistake; the foster children's mistakes are the contributing factor. Let's say the child didn't wash the dishes, I usually say to foster parents if it was your child what is it that you were going to do. She will say 'I was going to deny the child television', I will say 'Apply that to the foster child'. (JPT)

According to the Department of Social Development (2012b), discipline is a process which is aimed at teaching children self-discipline and is not a form of punishment, e.g. spanking, withholding food, name calling. Durand (2007) points out that fostering a child is a challenging and complicated task and that foster parents are not trained sufficiently to understand and solve the issues that arise when children are placed in their care. Children placed in foster care tend to display higher levels of emotional and behavioural disturbances as a result of their experiences (Böning \& Ferreira, 2013).

\section{Sub-theme 2.4 Foster parents' own experience of abuse}

From the narrative of one participant it became apparent that foster parents with a history of being abused and neglected sometimes abuse the foster child:

It could be that some of them were victims... The foster parent grew up being physically abused, in her life; in married life her husband was also beating her... It was when she beat the child... Most children ended up being abused and neglected by foster parents because of the things they themselves have gone through. Now most of them, I pick up that some of things they have not dealt with like emotional things that they hold in their hearts. Because of those things you have not yet dealt with and you are going to foster a child that is a teenager with a deviant behaviour. So that person will see beating the child as the best option to deal with the child or uttering painful words. (LPT)

Chamberlin (2014:291) indicates that one of the causes of child abuse is "intergenerational abuse". It is stated that parents with a continuous history of childhood physical abuse are potentially higher-risk physical abusers of children than those without a history of physical abuse (Romero-Martínez, Figueiredoa \& Moya-Albiol, 2013).

\section{Sub-theme 2.5 Foster parents' lack of understanding of foster care}

The findings of the study show that foster parents appear not to know or understand their responsibilities and the rights of the children. Foster parents are offered no or limited training on foster children's rights and the responsibilities of the foster parent.

Another thing that could be the most of foster parents are not aware of children's rights and their parental responsibility. As a parent I have responsibility to take care of the child. (EPT)

They don't understand foster care, they get surprised when you have to remind them that foster care is not about foster care grant... as a result of that you have to work very hard to make them understand and they usually don't understand... (MPT)

De Jager (2011) states that foster parents are expected by law to be able to do certain things and the law provides them with certain rights. Section 188 of the Children's Amendment Act 41 of 2007 (RSA, 2008) stipulates the responsibilities and rights of the foster parent:

(1) The foster parent has those parental responsibilities and rights in respect of the child as set out in - (a) the order of the children's court placing the child in the foster care of that foster parent; ... (d) an order of court assigning parental responsibilities and rights in terms of section 23; and (e) a foster care plan between the parent or guardian of the child and the foster parent.

In terms of section 23 of this Act, it grants (a) contact with the child; or (b) care of the child". According to Mnisi (2015), foster parents are not clear about what is expected of them.

\section{Sub-theme 2.6 Foster parents' lack of understanding of foster child's needs}

The study showed that foster parents fail to realise that foster children need attention. This creates confusion to the extent that the child's behaviour is not understood. 
Sometimes the child may act out or change behaviour because he/she wants attention. When the behaviour of the child changes it's because foster parents don't have time with the foster child. The foster child is the child that has lost his/her parents so the child needs to deal with the death/loss of his parents. The child needs to adapt in the new family. (CPT)

When they say you are an orphan child, you are a foster care child, so the problem is that foster children are in a classified box so that also irritates and frustrates the child, which is why they act out because they feel like they have this label which they have to live by for the rest of their life. (BPT)

The child's behaviour as well, there is this tendency of foster parents that a foster child should behave as a saint. The foster parent was experiencing difficulties in dealing with the child's behaviour as she was starting to steal, starting to go out with other kids as she was that child who used to stay at home but now, she wants to experiment. (IPT)

Studies show that foster children need to adjust to life in the foster family. Crosson-Tower (2008) emphasises that foster children must adjust to separation from their family, new surroundings, possibly a new school, and the foster parents' own children, neighbours and friends. On the other hand, Mnisi (2015) highlights that foster children are placed in foster care with emotional stress or baggage and discomfort from previous settings. This might hamper the adjustment of both the foster child and the foster parent. De Jager (2011) points out that the death of a parent is a great loss for children.

\section{Theme 3: Factors in social work foster care services that contribute to neglect and abuse}

Participants in this study pointed out various factors relating to social work foster care that contribute to the abuse and neglect of foster children. Factors that contribute include high caseloads, a shortage of manpower, a lack of parental training and insufficient supervision.

\section{Sub-theme 3.1 High foster care caseloads per social worker}

The following comments attest to high foster care caseloads per social worker and the implication of this for social workers and their clients:

On my side I find it very difficult when I have placed a child because of my workload I will only be able to see the file after two years when I have to review. (CPT)

Yes, our caseload is higher, on top of that we lack resources even if you feel you can go the extra mile. (JPT)

We neglect our people because of pushing numbers. If we can provide our people with services, we won't have a problem. (JPT)

The literature reveals that the foster care system in South Africa is not coping (Dhludhlu \& Lombard, 2017; Kanyane, 2015; Naicker, 2021). It is obvious that foster children are neglected by social workers owing to high caseloads. Even if the child is abused, the social worker may only get to know about it after two years when it is time to review the placement. The study by Ngwabi (2014) reveals that since the adoption of the Children's Act 38 of 2005 (RSA, 2005), social workers are required to deal with a lot of administration to process foster care placements and must concentrate on desk work, processing foster care papers because so many forms must be completed. It is mentioned that the backlog has made social workers lose their self-esteem, become deskilled and not able to use their social work skills - they are "pushing numbers" instead rendering high-quality services (Ngwenya, 2011). The huge foster care backlog has resulted in social workers being unable to obtain new court orders for children with expired court orders, with the danger of several thousands of children having their FGC lapsed because of expired court orders. This necessitated the intervention of the North Gauteng High Court to prevent the lapsing of the FCG in 2011, 2014, 2017 and 2020 (Naicker, 2021). This transferred the decision to extend a placement from the social workers to the courts as an administrative process, leaving foster children vulnerable without supervision services. 
Sub-theme 3.2 Shortage of manpower and too few resources to manage foster care effectively

It is obvious from the findings that social workers do not perform their work as it is supposed to be done. Participants asserted that there is a shortage of social workers, social auxiliary workers and coordinators in offices. Social workers are unable to monitor their cases well to a point where foster children can be abused and neglected by foster parents without this being noticed owing to a lack of resources.

We have a shortage of social workers, because you can't control your caseload, and there are no social auxiliary workers, the supervision of cases, that's where they get in. (MPT)

Again, we turn to overlook some of the other things because of caseload, we have too much of caseload with little resources. So, this little resources contribute to neglect and abuse in this manner, we don't normally do foster care supervisions as it has to be done. (IPT)

We don't have cars, you only do home visits once a week and the minute you get an opportunity to do home visits, it is when you have to do your reviews and placements of new files. (IPT)

So, we will just have to wait, even now the files that are on my table needs to be captured in my system, others need to be duplicated to assist SASSA with their backlog. Currently as we speak our photocopying machine is broken, I can't print the reports that need to be in court. (BPT)

The Minister of Social Development at the time, Bathabile Dlamini (Kanyane, 2015) agreed with the participants of this study that there was a shortage of social workers and supervisors. As stated by Ngwenya (2011), the lack of resources frustrates and angers social workers as it hinders them from providing high-quality services to clients. The participants in Ngwabi's (2014) study also mentioned that a lack of resources, such as computers and printers, hindered them from delivering effective foster care. Although a lack of manpower and resources has been highlighted for years, it remains a need.

\section{Sub-theme 3.3 "Forced" foster care placements}

Participants mentioned that some foster parents felt obliged to provide care and protection to foster children and that imposed foster care placements pose the threat that the children might be abused and neglected.

Another thing is... I don't know how to put it, let me say a forced foster care placement because in some cases some people are forced to take care of the children because the children's parents are deceased. Another reason is that they are the only surviving relatives, so they are forced to take the children. Age maturity because other kids foster other kids, the foster parent is not mature enough to foster the children, but just only because it is her siblings, she is forced to take care of the children and she still has to enjoy life; that is when neglect starts. (IPT)

Some foster parents were forced by circumstances to foster the children or other reasons. Our families, especially blacks, if [you] are my sibling when you die, I will have to look after your children or if I die you will look after my children. You feel like it is your responsibility to do that, you don't get any support even if you struggle you have to deal with the situation on your own. (FPT)

Mnisi (2015) states that in many cases foster parents, especially relatives, feel obliged to take responsibility and to provide care for the children. Ngwenya (2011) and Van der Riet (2009) point out that HIV/AIDS is the main reason why many children are taken into foster care by their relatives. This factor seems to link with family seeing foster care as the only way to obtain financial assistance when caring for a relative's child.

\section{Sub-theme 3.4 Inadequate assessment and training of foster parents}

Participants were of the view that foster parents are not always properly assessed and trained to deal with foster children when challenges arise.

According to the Act it is a must, you have to train a foster parent and you need to see if the person is ready to foster the child and in some of the files when you look at them, there is no 
police clearance, there is Form 30 which includes whether the person has abused the child before, you see. (IPT)

Because we don't have time to train foster parents so if we really had time to train them by making them ready to know what to expect and how to deal with the situation that they will encounter. (CPT)

... that's when the child will be neglected because everyone has his/her corner, that is why we need to train foster parents so that the other children in the family can accept foster children.

( JPT)

Assessments are not properly done and foster parents often do not know what is expected of them and how to deal with the challenging behaviour of foster children. According to Carter (2013), there is uncertainty about how to assess the prospective foster parent. De Jager (2011) argues that a holistic assessment should be made of a prospective foster parent's family and way of life. Mnisi (2015) recommends pre-fostering support programmes, debriefing programmes for foster children who experienced trauma, bereavement programmes and parenting skills programmes to support foster parents and children, and prevent the transfer of foster children from one placement to the next.

\section{Sub-theme 3.5 Inadequate monitoring, supervision and support of foster care placements}

There is a direct link between social workers' inability to do foster care supervision, and a lack of manpower and resources. A sense of frustration in the participants was observed as these factors are out of their control.

We don't normally do foster care supervisions as it has to be done. After you have placed the child in foster care, after six months you have to do a progress report and you have to do supervisions. (IPT)

Our failure as the organisation is the supervision of cases. We don't do supervision of cases and we don't monitor these cases. We only monitor closely when the case has been reported, or when we must review. We don't have enough time to monitor the whole caseload, it is difficult for us to monitor it. (MPT)

Yes, you know I can say if a continuous monitoring by social workers exists, it will help to know that children in foster care are properly cared for and also home visits are helping a lot. (GPT)

The Department of Social Development (2012a) acknowledges that the shortage of social workers leads to foster care backlogs and the inability to render supervision services. The Guideline for the effective management of foster care in South Africa (DSD, 2009) divides foster care into the assessment phase, placement phase and the supervision and support phase. In her study "Factors influencing the decisionmaking processes of social workers rendering foster care services: a decision-making matrix as a guideline for social workers" Naicker (2021) identified a lack of foster care plans and multidisciplinary reports on files of foster care social workers and found that supervisors seem not to be involved in the supervision phase unless the social workers request them to be. In their study Böning and Ferreira (2013) indicated that social workers in foster care were aware of the content and importance of foster care plans, but that the execution of the plans was not always feasible due to high caseloads. There is also insufficient tracking of children within the child protection system from one placement to the next (Children's Institute, 2017).

\section{Sub-theme 3.6 Inadequate provision for differences between the foster child and foster family during placement}

Participating social workers pointed out that during the placement of foster children, similarities and differences between the child and parent are not considered. This oversight creates instability of the foster care placement, which in turn leads to conflicts and forces the children to do things they are not used to. 
Culture and religious aspects seem not to be considered, and as a result some foster parents force their foster children to follow the new family's belief system.

Like culture is a problem where the foster child comes from a Christian family and they don't perform ancestral rituals but now the child is in this family. The foster parent is the aunt and is married into a family that does things differently so the child needs to adapt to ancestor's belief. (CPT)

When we speak of the Rasta case, it is the belief system; sometimes we force our belief systems onto the children which causes conflicts. (FPT)

So, the problem starts when the child is instructed to follow what is done in the family or (be) expelled. So, the child feels he/she has his/her own beliefs, you understand, why he/she should change. (CPT)

Culture has an influence on foster parents' daily decision making and it influences the foster children (De Villiers, 2008). One of the decisions a social worker must make is whether to put a child in related or unrelated foster care (Naicker, 2021). In related foster care culture is usually taken into account, but personality differences are not always considered. With unrelated foster care the social worker often uses a pool of pre-screened foster parents (Naicker, 2021). This indicates that differences and similarities might not be taken into consideration.

\section{CONCLUSIONS}

The authors wanted to gain an understanding of whether foster children within the South African context are indeed abused and neglected by foster families. The 13 social workers in the sample had no statistical register to report such cases, but indicated that a total of 236 foster children were abused and neglected during 2016 and 2017 in the Botshabelo Township. Some participants reported a higher number of cases of neglect and abuse of the foster children, while others identified a smaller number of such cases from their caseloads. One of the limitations of the study is that it covered a small sample within a specific area. However, the results can serve as an indication of what might be happening in other areas of the country. The social workers categorised the abuse and neglect they observed as physical neglect, physical abuse, emotional abuse and neglect, as well as sexual abuse and rape.

A variety of explanations were provided to answer the question of why foster care children are abused and neglected, namely factors related to the foster parent, the foster child, the foster parent-child relationship, the child's family, the community, foster care services and other organisations. The two factors explained in the most detail by participants and thus discussed in the article are related to foster parents and factors in social work foster care services. It was stated that foster parents misused the FCG for their own needs or those of their family. This seemed to occur when foster parents are poor or unemployed, and can be related to the use of the FCG as part of poverty alleviation. Feedback from participants also revealed that foster parents appeared to be poorly equipped or unable to parent foster children. Foster parents seemed to be confused about how to handle or discipline foster children, who often displayed difficult or defiant behaviour. It was indicated that a foster parent who experienced abuse as a child or adult could be prone to abuse his or her foster child. Social worker participants also stated that foster parents often did not understand the purpose of foster care or the needs of foster children who came into foster care traumatised and vulnerable.

The study revealed several factors in foster care services that may contribute to the abuse and neglect of foster children. These included factors that have already identified within the South African child protection system for years, namely high foster care caseloads per social worker, a shortage of manpower and too few resources to do social work effectively, "forced" foster care placements, inadequate assessment and training of foster parents, inadequate monitoring, supervision and support of foster care placements, and inadequate provision for differences between the foster child and foster family during placement. 
It is unlikely that one single factor will lead to the abuse or neglect of a foster child in a specific family. These factors co-exist and are often linked or related.

\section{RECOMMENDATIONS}

The following recommendations are made based on the findings of the study.

\section{Policy}

- The responsibility for the extension of court orders should be returned from the court to social workers who can monitor the welfare of foster children.

- A long-term solution for the foster care crisis should be developed by all stakeholders.

- The Department of Social Development should develop clear guidelines for a manageable foster care caseload.

\section{Practice}

- Data on the abuse and neglect of foster children should be gathered, monitored and evaluated on an office, provincial and national level.

- The wellness of foster children, including abuse and neglect, should be tracked as they are transferred from one alternative placement to another.

- Social service delivery should focus on continuous rigorous monitoring of foster placements, including the use of a foster care plan.

- Support for foster parents should be extended by implementing group work and community work as methods.

- Foster care should be a stand-alone programme meaning that there should be dedicated social workers who focus only on foster care.

\section{Education}

- Awareness should be created of the occurrence of abuse and neglect of foster children and a procedure developed to investigate allegations.

- Social workers should be trained to use additional assessment tools and criteria on age, race, religion, culture and linguistic background to screen prospective foster parents to avoid problems during and after placements.

- A foster care orientation should be introduced to prospective foster parents.

- Various pre- and post-fostering support programmes could be implemented, for example, a programme to prepare foster children to join their new families, bereavement counselling for foster children after losing their loved ones, and parent training programmes in the form of workshops or group sessions.

\section{Research}

- More research should be undertaken within wider contexts to confirm the occurrence of abuse and neglect of foster children as well as factors influencing this phenomenon.

- More research could also be done to find feasible solutions to the foster care crisis.

The purpose of foster care is to protect children within a safe environment. Yet it seems that foster care is not the safe place we believe it to be. However, an awareness that abuse and neglect of foster children are happening and knowledge of possible reasons why this is happening can assist social workers in taking steps to prevent or limit such abuse and neglect. 


\section{REFERENCES}

ADOPTION AND FOSTER CARE ANALYSIS AND REPORTING SYSTEM REPORT. 2020

[Online] Available: https://www.acf.hhs.gov/cb [Accessed: 2021/06/01].

BABBIE, E. 2007. The practice of social research. 11th ed. Belmont. California: Wadsworth.

BIEHAL, N., ELLISON, S., BAKER, C. \& SINCLAIR, I. 2010. Belonging and permanence. Outcomes in long-term foster care and adoption. London: British Association for Adoption and Fostering.

BIEHAL, N. \& PARRY, E. 2010. Maltreatment and allegations of maltreatment in foster care. A review of the evidence. Social Policy Research Unit. Heslington: University of York.

BOLTON, F. G., LANER, R. H. O. \& GAI, D. S. 1981. For better or worst? Foster parents and foster children in an officially reported maltreatment population. Children and Youth Services Review, 3: 37 53.

BöNING, A. \& FERREIRA, S. 2013 An analysis of, and different approach to, challenges in foster care practice in South Africa. Social Work/Maatskaplike Werk, 49(4): 519-566.

CARTER, J. B. 2013. A contextually appropriate protocol in social for the assessment of prospective foster parent in South Africa. Johannesburg: University of Johannesburg. (Masters' dissertation)

CAVARA, M. \& OGREN, C. 1983. Protocol to investigate child abuse in foster care. Child Abuse and Neglect, 7: 87-295.

CHAMBERLIN, M.S.B. 2014. What causes child abuse? Citizens identify causes of child abuse and suggest prevention strategies. Journal of Sociology and Social Work, 2(1): 83-301.

CHILDREN'S INSTITUTE. 2017. Tracking child abuse cases through the child protection system at five selected sites in South Africa. Research Report. Children's Institute. Cape town: University of Cape Town.

CRESWELL, J.W. 2009. Research design: qualitative, quantitative and mixed methods approaches. London: SAGE.

CROSSON-TOWER, C. 2008. Understanding child abuse and neglect. $7^{\text {th }}$ ed. Boston: Pearson Education.

DE JAGER, E. 2011. Foster care of aids orphans: Social workers' perspectives. Stellenbosch: University of Stellenbosch. (MSW dissertation)

DEPARTMENT OF SOCIAL DEVELOPMENT (DSD). 2009. Guidelines for effective management of foster care in South Africa. Pretoria: Government Printer.

DEPARTMENT OF SOCIAL DEVELOPMENT. 2012a. Information guide on the management of statutory services in terms of the Children's Act 38 of 2005. Pretoria: Government Printers.

DEPARTMENT OF SOCIAL DEVELOPMENT. 2012b. Integrated parenting framework. Pretoria: Government Printers.

DE VILLIERS, A. 2008. The role of the social worker in the reunification of foster children with their biological parents. Stellenbosch: University of Stellenbosch. (Masters dissertation)

DHLUDHLU, S. \& LOMBARD, A. 2017. Challenges of statutory social workers in linking foster care services with socio-economic development programmes. Social Work/Maatskaplike Werk, 53(2): 165-185.

DURAND, B. K. 2007. The support and training of foster parents. Stellenbosch: University of Stellenbosch. (Masters thesis) 
FARMER, E. \& MOYERS, S. 2008. Kinship care, fostering effective family and friend placements. London: Jessica Kingsley Publishers.

GIL, E. 2006. Helping abused and traumatized children: Integrating directive and non-directive approaches. New York: Guilford Press.

HALL, H. 2013. The impact of postmodernism on the functioning of young adults. Pretoria: University of Pretoria. (Doctor of Philosophy Thesis)

HSRC. 2012. Child maltreatment prevention readiness assessment: South Africa. Cape Town: South Africa.

HUNT, J., WATERHOUSE, S. \& LUTMAN, E. 2008. Keeping them in the family: Outcomes for children placed in kinship care through care proceedings. London: British Association for Adoption and Fostering.

JAMIESON, L., BERRY, L. \& LAKE, L. 2017. South Africa Child Gauge 2017. Cape Town: Children's Institute, University of Cape Town.

KANYANE, M. E. 2015. Child support grant versus foster care grant. Pretoria: University of Pretoria. (Masters dissertation)

MAREE, K. 2007. First steps in research. Pretoria: Van Schaik Publishers.

MCGUINNESS, T. M. \& SCHNEIDER, K. 2007. Poverty, child maltreatment and foster care. Journal of the American Psychiatric Nurses Association, 13(5): 296-303.

MNISI, R.M. 2015. Factors contributing to the breakdown of foster care placements: foster parents' and adolescents' perspectives. Pretoria: University of South Africa. (Masters dissertation)

NAICKER, P. 2021. Factors influencing the decision-making processes of social workers rendering foster care services: A decision-making matrix as a guideline for social workers. Pretoria: University of South Africa. (Doctoral thesis)

NGWABI, N. T. 2014. Barriers in implementing foster care services within a developmental approach in Inkangala District, Mpumalanga. Pretoria: University of Pretoria. (Masters dissertation)

NGWENYA, P. M. 2011. Factors contributing to the foster care backlog: Service providers' perspectives and suggestions. Pretoria: University of South Africa. (Masters' dissertation)

NIXON, S. \& VERITY, P. 1996. Allegations against foster families. Foster Care, 84: 11-14.

PAAT, Y. 2013. Working with immigrant children and their families: An application of Bronfenbrenner's Ecological Systems Theory. Journal of Human Behavior in the Social Environment, 23(8): 954-966.

PRETORIUS, D. \& PISTORIUS, A. 2012. Introduction and definitions of child abuse In: PRETORIUS D., MHLOKAZI, A. J., HLAISE, K.K. \& JACKLIN, L. (eds.). Guideline and applications for primary health care practitioners. Cape Town: Juta.

REPUBLIC OF SOUTH AFRICA (RSA). 2005. Children's Act 38 of 2005. Government Gazette, Vol. 492, No. 28944 (19 June 2006). Pretoria: Government Printer.

REPUBLIC OF SOUTH AFRICA (RSA). 2008. Children's Amendment Act 41 of 2007. Government Gazette, Vol. 513, No. 30884 (18 March 2008). Pretoria: Government Printers.

ROMERO-MARTÍNEZ, A., FIGUEIREDO, B. \& MOYA-ALBIOL, L. 2013. Childhood history of abuse and child abuse potential: The role of parent's gender and timing of childhood abuse. [Online] Available: http://dx.doi.org/10.1016/j.chiabu.2013.09.0 [Accessed: 2019/01/12].

SCHILLER, U. \& STRYDOM, M. 2018. Evidence-based practice in child protection services: Do we have time for this? Social Work/Maatskaplike Werk, 54(4): 407-420. 
SCOTTISH GOVERNMENT. 2010. The national guidance for child protection in Scotland. [Online] Available: http:www.gov.scot>resource>doc [Accessed: 2016/06/23].

SILVERMAN, D. 2010. Doing qualitative research: a practical handbook. $3^{\text {rd }}$ ed. London: SAGE SOUTH AFRICAN SOCIAL SECURITY AGENCY. 2020. Report on Foster Care. December 2020. Internal document.

SWAIN, V. 2006. Allegations in foster care: A UK study of foster carers' experiences of allegations. The Fostering Network: London.

TARREN-SWEENEY, M. 2006. Patterns of aberrant eating among pre-adolescent children in foster care. Journal of Abnormal Child Psychology, 34(5): 621-632.

THE FOSTERING NETWORK. 2004. Fostering can never feel the same for us: A study of foster families that have been the subjects of an allegation. London: The Fostering Network.

THE FOSTERING NETWORK. 2020. Fostering statistics. [Online] Available: https://www.thefosteringnetwork.org.uk/advice-information/all-about-fostering/fostering-statistics [Accessed: 2021. 06.04].

VAN DER RIET, K.E. 2009. Foster care: The experiences of birth children. Pretoria: University of South Africa. (Masters' dissertation)

WORLD HEALTH ORGANISATION AND INTERNATIONAL SOCIETY FOR PREVENTION OF CHILD ABUSE AND NEGLECT. 2006. Preventing child maltreatment: A guide to taking action and generating evidence. Geneva: WHO Press. 